\title{
Percepções e afetos de policiais federais: interações com estudantes estrangeiros
}

Silvia Garcia Nogueira*

\section{Resumo}

Os contatos de estrangeiros com representantes do Estado que desempenham papéis de controle da ordem social e repressão à sua infração frequentemente são marcados por um clima de desconfiança. No caso dos migrantes internacionais, a apresentação à Polícia Federal, por qualquer motivo, representa um momento tenso em que paira o sentimento de se ter feito algo errado, mesmo quando isso não procede. Paralelamente, intelectuais voltados para o estudo de imigrantes no Brasil têm dado preferência a investigar os processos migratórios na perspectiva dos que migram ou dos que os recebem, mas tendem a deixar de lado os agentes estatais mediadores que definem a condição de regularidade e legalidade de estrangeiros no país. A referência a eles tende a carregar pressupostos e pré-conceitos, cujo ponto de partida e chegada é o entendimento de que estrangeiros e agentes estatais estão em posição de confronto em grande parte das vezes. Diante disso, este trabalho pretende discutir etnograficamente o modo como alguns representantes da Delegacia de Migração da Polícia Federal em João Pessoa (PB) percebem a si mesmos no desempenho de seu oficio policial no contato cotidiano com estrangeiros regulares na Paraíba, suas visões sobre a instituição à qual pertencem e suas percepções de mundo no que tange ao contato com migrantes internacionais. Os primeiros dados da pesquisa apontam para a sensibilidade de alguns membros da Delegacia que superam as expectativas meramente burocráticas no desempenho das funções profissionais cotidianas, revelando desejos e práticas de solidariedade e hospitalidade em relação a estrangeiros regulares no estado..

\section{Palavras-chave}

Polícia Federal. Estudantes internacionais. Migrações.

\footnotetext{
* Silvia Garcia Nogueira é investigadora visitante/pós-doutoranda no Instituto de Ciências Sociais da Universidade de Lisboa (ICS / ULisboa), professora da graduação e do Programa de Pós-Graduação em Relações Internacionais da Universidade Estadual da Paraíba (UEPB). É mestre e doutora em Antropologia Social pelo Museu Nacional (UFRJ) e jornalista formada pela PUC-Rio. Tem publicado artigos nas áreas de antropologia da comunicação, mídia e relações internacionais, e cooperação acadêmica internacional. É co-organizadora dos livros "Antropologia da Comunicação de Massa" e "América Andina: integração regional, segurança e outros olhares". Email: snogueirari@gmail.com
} 


\section{Abstract}

The contacts of foreigners with representatives of the State who play significant roles regarding control over social order and repression are often marked by an atmosphere of distrust. In the case of international migrants, their presentation to the Federal Police for any reason represents a tense moment, in which there is a feeling of having done something wrong even when this is not the case. At the same time, intellectuals who focused on the study of immigrants in Brazil have given preference to investigate migratory processes from the perspective of both those who migrate or those who host them, but tend to leave aside the mediating state agents in charge of defining the condition of regularity and legality of foreigners in the country. Reference to them leads to assumptions and preconceptions, which tend to point to the unchangeable understanding that foreigners and state agents are most often in a position of confrontation. Therefore, this study aims at discussing ethnographically how some representatives of the Federal Police Migration Department in João Pessoa call up themselves to the duty of their police service, in the daily contact with regular foreigners in Paraíba, their visions concerned with the institution to which they belong, and their perceptions of the world regarding contact with international migrants. The first data of the research point to the sensitivity of some members of the Police Station who surpass the purely bureaucratic expectations in the performance of the daily professional functions, revealing desires and practices of solidarity and hospitality in relation to regular foreigners in the state.

\section{Keywords}

Federal Police. Internationals students. Migrations.

\section{Introdução}

Os contatos de estrangeiros com representantes do Estado que desempenham papéis de controle da ordem social e de repressão à sua infração frequentemente são marcados por um clima de ansiedade e desconfiança. No caso dos migrantes internacionais, a apresentação à Polícia Federal por qualquer motivo representa um momento tenso, em que paira o sentimento de se ter feito algo errado, mesmo quando isso não procede e se está em situação regular.

Em parte, a explicação para o desconforto reside no fato da existência de um ambiente construído pelos Estados no pós-11 de setembro de 2001, cujo pressuposto tornou-se o de que a segurança internacional estaria ameaçada por "terroristas" dispostos a cometerem atentados em quaisquer hora e 
lugar. Uma significativa consequência daí decorrente foi a adoção pelos Estados de medidas e políticas migratórias voltadas para (ou em nome de) a defesa de sua soberania e de seus interesses nacionais.

Os migrantes internacionais, então, passam a reagir norteados por um quadro simultaneamente imaginário e real de endurecimento no controle sobre estrangeiros. Na perspectiva do indivíduo, ocorre uma exacerbação do sentimento de medo, Na do Estado (e de seus representantes), o "outro" é tratado como ameaça (NOGUEIRA, 2013), já que, conforme Póvoa-Neto (2005, p.297), a própria condição de migrante passa a ser criminalizada. No campo das Relações Internacionais, portanto, conectado diretamente à segurança, o tema das migrações internacionais passa a ser matéria de alta política (MENEZES, 2007).

O Estado brasileiro, a partir do Governo Lula (2003-2010), voltou sua política externa para a cooperação internacional do tipo "Sul-Sul", em princípio marcada por uma orientação mais horizontalizada em relação a uma do tipo "Norte-Sul". O estreitamento de laços políticos entre os países ocorre em grande medida a partir da cooperação educacional, na qual o Brasil se transformou em uma importante referência de estudantes internacionais oriundos de tais países do "Sul", especialmente os integrantes da Comunidade de Países de Língua Portuguesa (CPLP). Um referencial sobre os reflexos dessa política pode ser visto nos resultados do Censo de 2010, do Instituto Brasileiro de Geografia e Estatística (IBGE), que aponta que quase dobrou o número de imigrantes residentes no país em uma década. Em 2010, eram 268.201 imigrantes vivendo no Brasil, contra 143.644 imigrantes, em 2000, configurando um aumento de $86,7 \%$ (sendo a região Sudeste a que mais vem recebendo imigrantes nesse período de tempo) ${ }^{1}$.

No que se refere especificamente às migrações de estudantes que escolhem o Brasil como destino para qualificação acadêmica, dados do Ministério das Relações Exteriores relativos ao Programa de EstudanteConvênio de Graduação (PEC-G) e de Pós-Graduação (PEC-PG) ${ }^{2}$ apontam que, entre 2000 e 2013, o país recebeu 7172 alunos estrangeiros do que pode

\footnotetext{
${ }^{1}$ Dados retirados da reportagem "Número de imigrantes no Brasil quase dobra na década; SP e PR são os principais destinos", da Folha de S. Paulo. Disponível em: http://noticias.uol. com.br/cotidiano/ultimas-noticias/2012/04/27/ numero-de-imigrantes-morando-no-brasilquase-dobra-em-dez-anos-sp-e-pr-sao-os-principais-destinos.htm.

2 Informações retiradas do site do MRE. Disponível em: www.dce.mre.gov.br/PEC/G/ historico.php e www.dce.mre.gov.br/PEC/PG/historico.php. Acesso em 13 agosto de 2014.
} 
ser entendido como do "Sul" (em oposição ao "Norte", com relações de convênio hierarquizadas e subalternizadas) dentro do PEC-G, e 2166 no PEC-PG. Um detalhamento maior aponta que desses totais, na graduação, o predomínio foi de estudantes africanos (6001 alunos no período, sendo que em 2013 foram 255), seguido por latino-americanos (1636 no total, 132 em 2013) e asiáticos (39 no total, 34 em 2013). No PEC-PG, com um total de 2166 no mesmo período, a distribuição foi a seguinte: 1625 alunos provenientes das Américas, sendo 208 em 2013; 465 africanos, 76 em 2013; 76 asiáticos, sendo 2 em 2013.

Foi justamente com uma série de indagações sobre o fenômeno de modo geral e em particular com uma curiosidade sobre os estrangeiros na região Nordeste do Brasil - pouco analisados numa comparação com o Sul e o Sudeste do país - que desde 2009 venho pesquisando os estudantes internacionais que migram por motivos de qualificação profissional para a Paraíba $^{3}$, primeiramente africanos e recentemente timorenses. As pesquisas, no entanto, levaram a nossa equipe a contatos diretos e indiretos com órgãos distintos (universidades públicas, secretarias de governo, consulados e embaixadas, entre outros), além dos alunos estrangeiros, claro. Entre as organizações públicas, a Polícia Federal (PF) foi a que mais me chamou a atenção, por ter se configurado como o órgão que melhor nos recebeu e mais nos apoiou no momento da coleta de dados.

Desde o início, o então Superintendente Geral da PF não somente autorizou a realização da pesquisa junto à Delegacia de Polícia de Imigração (Delemig/PB) ${ }^{4}$ como ressaltou a importância do tema. Ademais, um pouco

\footnotetext{
${ }^{3}$ A pesquisa vem sendo desenvolvida no âmbito dos projetos intitulados "Migrantes em trânsito na Paraíba: políticas, normatizações e mapeamento de estrangeiros com vistos de trabalho, negócios e estudo" (2009-2010, dentro do PIBIC/UEPB); “Cooperação TécnicaEducacional. Um estudo sobre as relações Brasil-África a partir da experiência de estudantes africanos em universidades públicas na Paraíba" (2010-2011, dentro do PIBIC/UEPB); e "As migrações internacionais: sobre os conceitos teóricos e o aprofundamento da análise da situação contemporânea dos imigrantes brasileiros" (2011-2014, apoiado pelo PROPESQ/ UEPB), que abarcou ainda um projeto PIBIC/UEPB (cota 2013-2014) voltado para a cooperação educacional estabelecido entre a Universidade Estadual da Paraíba e o Fundo Nacional de Capital Humano do Timor-Leste, com acompanhamento dos 33 estudantes timorenses que estudam em graduações e pós-graduações da UEPB.

${ }^{4}$ Agradeço a autorização dada entre 2009 e 2011 pela Superintendência da Polícia Federal na Paraíba para a realização da pesquisa. Em especial, agradeço ainda àqueles que tiveram paciência de serem entrevistados, muito particularmente a uma pessoa que tem sido minha principal fonte de consulta desde sempre, e aos estudantes com os quais eu e os alunos da equipe de pesquisa mantivemos contatos ao longo do tempo. Finalmente, agradeço a Maria Claudia Coelho e Susana Durão a oportunidade de participar desta coletânea.
} 
antes até de eu sequer pensar em estudar o assunto, por uma situação particular, uma das pessoas do setor de imigração era membro tanto quanto eu do Comitê Paraibano de Educação em Direitos Humanos, o que na época fazia com que nos encontrássemos com alguma frequência. Aliás, esse fato me inspirou a aproximar-me daquela organização e instaurou uma série de indagações sobre pressupostos diante de representantes estatais. De qualquer modo, o contato direto com a Delemig revelou facetas inesperadas em relação ao que eu mesma pressupunha ser o tratamento dispensado ao público: um atendimento formal, distanciado - imaginário formado por expectativas externas que rondam o próprio trabalho policial burocrático, de controle e de investigação. Minha primeira surpresa ocorreu quando, tendo enviado uma aluna da equipe de pesquisa para fazer a coleta de dados quantitativos sobre estudantes estrangeiros na Paraíba, um agente prontamente se ofereceu para ajudá-la com a tarefa. Isto porque inexistia um banco de dados compilados, sendo preciso consultar um a um os registros de todos eles, para fazer a contagem. Outra surpresa foi que os ouvidos costumavam contar casos de experiências negativas e insatisfatórias de seus contatos com outros postos da PF no país, mas não foi feita nenhuma reclamação específica no que se refere à Delemig / PB.

O desenrolar do estudo sobre os alunos internacionais e a aproximação com alguns membros da PF possibilitaram ainda conhecer alguns casos contados por ambos os grupos de situações em que as ações dos representantes estatais (agentes e administrativos, principalmente, pelo contato direto com os estrangeiros) ultrapassaram os padrões formais e burocráticos de comportamentos e sentimentos (ou ausência deles) esperados pela organização (e de certo modo, pelos usuários dos serviços também).

O que se pôde perceber foi a presença de afetos ${ }^{5}$ vindos de um agente público, no exercício da profissão, em situações interacionais dentro de uma organização marcada pela racionalidade típica do trabalho policial, com expectativas de frieza e distanciamento emocional de seus quadros $\neg$. As

\footnotetext{
${ }^{5}$ De acordo com Gondim e Siqueira (2004, p.211):

"os afetos abarcariam os sentimentos, os humores e os temperamentos, que teriam em comum sua maior persistência no tempo e sua relação com aspectos cognitivos. Os sentimentos não estariam relacionados à prontidão da ação tanto quanto às emoções, mas à interpretação subjetiva da situação que pela persistência do objeto na memória faria perdurar o afeto em relação a ele".
} 
histórias contadas incluíam desde funcionários que tiravam do próprio bolso a ajuda financeira para a renovação de vistos a estudantes em momentos de dificuldades econômicas - passando por orientações detalhadas sobre como agir em alguns casos - até um agente que foi apelidado carinhosamente por todos de "embaixador do Cabo Verde" por ser convidado a frequentar festividades da comunidade de estudantes na cidade. Fatos inesperados aos olhos distantes de quem não participa desse cotidiano muito particular.

De longe, nesse sentido, os intelectuais estiveram mais voltados para o estudo de imigrantes no Brasil na perspectiva dos que migram ou dos que os recebem, tendendo a deixar de lado como objetos de pesquisa os agentes estatais mediadores que definem a condição de regularidade e legalidade de estrangeiros no país. Os pontos de partida e de chegada têm sido o entendimento de que estrangeiros e agentes estatais estão em posição de confronto e conflito em grande parte das vezes.

Diante disso, este trabalho pretende discutir etnograficamente o modo como alguns representantes da Delemig da Polícia Federal em João Pessoa (PB) percebem a si mesmos no desempenho de seu oficio policial, nas interações cotidianas com estrangeiros regulares na Paraíba, suas visões sobre a instituição à qual pertencem e suas percepções de mundo no que tange aos estudantes internacionais. A chave teórica analítica utilizada que parece mais se adequar aos afetos envolvidos nas situações pesquisadas gira em torno das noções de "hospitalidade" e "solidariedade". Estas estão contidas implícita ou explicitamente na máquina burocrático-formal da PF e na incorporação pelos funcionários de "carne e osso", como disse um deles, de tais noções na realização de suas atividades profissionais. Ainda, em depoimentos de estudantes, várias foram as vezes em que apareceu o qualificativo de "hospitaleira" para falar sobre a sociedade paraibana, e nos relatos de alguns membros da PF "acolhimento" foi a palavra usada para designar o tratamento dado aos estudantes em distintas situações.

\section{Contatos e obrigações mútuas}

Os estudantes estrangeiros que ingressam no Brasil o fazem por meio de um visto de estudo já concedido pelo Ministério das Relações Exteriores e chegam a partir de uma relação previamente estabelecida entre os países (de origem e de destino) e as instituições envolvidas nesse processo, com regras e outras normatizações precisas. O primeiro contato com uma repartição da 
Polícia Federal ocorre em sua chegada, pois o estudante necessita fazer seu Registro Nacional de Estrangeiro (RNE) em até 30 dias de entrada no país.

Em princípio, o estudante deve procurar a PF de tempos em tempos, conforme o caso, para prorrogação de sua estada ou em caso de mudança de situação (por exemplo, pedido de transformação de visto). A validade máxima do RNE é de dois anos. O pedido de renovação do registro deve ser realizado com até 30 dias de antecedência - período previsto para a emissão da renovação. Exceder esse prazo pode significar uma autuação por irregularidade, caso o registro expire, e o novo documento não tenha sido emitido.

Em geral, os alunos em nível de graduação precisam se apresentar a cada ano, e os de pós-graduação, a cada dois anos. Esse prazo de um ano pode ser prorrogado por igual período até o final do curso. Mas existe o condicionamento ainda ao tipo de tratado de cooperação firmado entre o local de origem do estudante estrangeiro e o Brasil e/ou a instituição brasileira que o recebe. Caso ele não se apresente no prazo estipulado, é autuado, necessitando pagar uma multa atualizada diariamente, até 100 dias. Mas, em situação irregular, dependendo do acordo de cooperação que possibilitou sua vinda, o estudante pode receber uma notificação em até 8 dias após o prazo estipulado ou mesmo ser deportado.

Cabe ressaltar que para a Polícia Federal a situação de irregularidade é bem diferente da de ilegalidade. Segundo um agente ${ }^{6}$, o estrangeiro está irregular no país quando está sem visto; e está ilegal quando comete um crime. Ele exemplifica: "Se um brasileiro ou um estrangeiro em situação regular no país dá abrigo a um estrangeiro sem visto válido, ele está cometendo um crime, mas o estrangeiro sem visto válido está cometendo uma irregularidade". Conforme explicado pelo agente, existem 16 artigos de autuação que incidem sobre o estrangeiro. A PF trabalha diretamente referida à Lei 6.815, de 1980, ao Estatuto do Estrangeiro, por muitos considerado ultrapassado e uma herança da ditadura militar no Brasil por ter como foco principal a segurança nacional e não os direitos humanos ${ }^{7}$.

O RNE dá direito a um documento emitido em Brasília, confeccionado

\footnotetext{
${ }^{6}$ Para garantir o anonimato das fontes, como de praxe na pesquisa antropológica, nomes verdadeiros não serão apresentados, assim como qualquer tipo de característica, como cargo específico, tempo de serviço preciso ou sexo.

${ }^{7}$ Sobre documentação de estrangeiros no Brasil, ver Etcheverry (2007).
} 
no edifício sede da PF, que serve como identificação do estrangeiro em solo nacional. De acordo com outro funcionário da PF, o problema ocorre quando há uma demora na emissão dessa carteira de identificação (pela qual é preciso pagar uma taxa) e o estudante passa a ter uma série de dificuldades pela ausência da mesma. Sem a carteira, por exemplo, geralmente os bancos não abrem conta corrente para o estrangeiro, o papel contendo o número do protocolo do RNE. Segundo o funcionário, embora esse tenha sido o maior problema existente do ponto de vista burocrático para o estudante até poucos anos atrás, a orientação é a de que, se a carteira não chegar a tempo (até 3 meses), o estrangeiro está desobrigado a pagar uma nova taxa pela renovação da carteira.

Cabe dizer que, no instante do pedido da renovação do registro para o estudante, junto ao formulário próprio deve estar o histórico escolar do aluno emitido pela universidade na qual está matriculado. Para um agente, esse também é um fator de nervosismo dos requerentes junto à PF, pois a reprovação por falta em uma disciplina pode configurar um abandono da matéria, implicando um relatório enviado para a sede em Brasília.

A Delemig está subordinada à Superintendência Regional do Departamento de Polícia Federal na Paraíba, dividindo-se em Setor de Estrangeiros, Passaportes, Núcleo de Processamento de Mandados (Nuprom), Secretaria, Cartório, além da posição ocupada pelo delegado responsável. O serviço é predominantemente burocrático. Por isso mesmo, os policiais e os funcionários administrativos acabam desempenhando funções parecidas, embora as investigações fiquem a cargo dos policiais.

Em 2012, a delegacia contava com nove funcionários, incluindo a chefia, quatro a menos que em 2009, que contava com 13. Em 2013, segundo me foi informado, a situação era outra: estava-se vivendo um período de mudanças na Superintendência e na chefia da própria Delemig, havia gente se aposentando e concurso que admitia pessoal novo. Embora, por exemplo, o setor de Passaportes funcione dentro de um Shopping Center (na Casa da Cidadania), a sede da PF no estado foi deslocada para Cabedelo, município vizinho à capital paraibana, em um local de mais difícil acesso e, na interpretação de um funcionário, "isolado da vida cotidiana, do centro".

Em termos de atribuições e funções, o delegado exerce a chefia instaurando e presidindo inquéritos relativos à migração ou outra tarefa que lhe seja atribuída. Os agentes executam investigações (incluindo as sindicâncias, sobre as quais eles fazem relatórios para instrução de processos como permanência e naturalização, além de toda a instrução desses 
procedimentos) e participam de operações para prevenção e repressão a crimes da esfera da PF. No caso específico da Delemig, preferencialmente são eles que atendem estrangeiros. Ao escrivão cabe dar cumprimento às formalidades processuais, lavrar termos, autos e mandados, observando prazos necessários ao preparo, à ultimação e à remessa de procedimentos policiais de investigação, além de acompanhar o delegado em diligências policiais. Já aos administrativos cabe a execução de trabalhos que envolvam a aplicação das técnicas de pessoal, orçamento, organização, métodos e material. De acordo com um deles, "trocando em miúdos, meu trabalho envolve manutenção de arquivos, preparação de expedientes, além de atendimentos de solicitações e confecção de passaportes".

A capacitação policial é realizada na Escola Superior de Polícia (Cesp/ ANP), inaugurada em outubro de 2011, sendo esta resultado de uma reestruturação da antiga Coordenação de Altos Estudos de Segurança Pública (Caesp). O curso de formação policial oferecido pela Escola corresponde à última etapa do concurso público para ingresso nos cargos de Delegado, Perito Criminal Federal, Agente, Escrivão e Papiloscopista da Polícia Federal, e possui caráter eliminatório ${ }^{\text {. }}$

Segundo o site da Academia Nacional de Polícia (ANP), a Escola também é responsável pelo Curso Especial de Polícia (CEP), pré-requisito essencial ao acesso ao último nível da carreira. De acordo com uma pessoa da Delemig, esta funcionaria como uma pós-graduação lato sensu na área de ciências policiais. Depois de 10 anos de carreira policial, para efeitos de progressão funcional, é preciso fazer o referido curso e produzir uma monografia versando sobre um tema específico. No tocante às pesquisas e à divulgação acadêmico-científica, a Cesp promove publicações, como a Revista Brasileira de Ciências Policiais e a Revista Segurança Pública e Cidadania.

\section{Afetos de policiais de "carne e osso"}

Os funcionários (policiais e administrativos) do setor de imigração podem ser divididos em dois grupos, no que se refere ao contato e à interação com

\footnotetext{
${ }^{8}$ Fonte: Web site da ANP. Disponível em: http:/ / www.dpf.gov.br/anp/educacional/escolasuperior-de-policia. Acesso em 10 de abril de 2014.
} 
os estudantes internacionais. De um lado, aqueles que, sob uma face mais impessoal que a burocracia proporciona, tratam o estrangeiro regular de modo distanciado e formal. De outro lado, os que cumprem o seu ofício assim como os demais, porém são mais sensíveis aos problemas dos alunos, adicionando às informações puramente técnicas outras orientações relativas às diversas questões que afetam suas vidas. Conforme relatos de funcionários e estudantes, também ocorreram raramente casos de grosseria e descaso ${ }^{9}$, por um lado, e de relações muito próximas, por outro. Entre os ouvidos, esses dois tipos de situações são os mais raros e não abrangem necessariamente em especial a PF em João Pessoa, mas em outros estados por onde funcionários e estudantes circularam também ${ }^{10}$.

Dentro do primeiro grupo de funcionários da PF, um deles justifica seu posicionamento da seguinte forma:

"Eu uso o princípio da imparcialidade. Mas tem colegas que até tiram do próprio bolso, que pagam a prorrogação do estudante. Eu não, pois se um dos pré-requisitos é justamente o estudante ter condições de se manter, e se os brasileiros que vão para fora recebem tratamento formal, a partir da lógica da reciprocidade faço o mesmo que eles... Mas, claro, tudo dentro do respeito aos direitos humanos e do Estatuto do Estrangeiro. Inclusive, nossa formação na academia de polícia é bastante voltada para os direitos humanos e nosso hino tem uma parte sobre direitos humanos"11.

O que ele chama de "princípio de imparcialidade", em uma lógica racional, se encaixa perfeitamente em uma discussão levantada por Lutz,

\footnotetext{
${ }^{9}$ Ferreira et al. (2012) analisam as emoções discretas no trabalho (medo, raiva, surpresa, alegria, tristeza e asco), dizendo que estas ainda são pouco estudadas. A elas, os autores citam Mendonça (2003), acrescentando a retaliação (baseada no sentimento de injustiça e de indignação para com a organização). Embora estas não sejam o foco da pesquisa, uma hipótese de pesquisa para comportamentos "grosseiros" ou de "descaso" poderia ter relação com esta última.

${ }^{10}$ Nesta pesquisa, a verificação da veracidade das informações em relação a esses casos não foi uma preocupação, já que, como de praxe na pesquisa antropológica e na abordagem metodológica escolhida, a tendência foi valorizar os relatos nativos, sem julgá-los ou ao conteúdo do que relatam.

${ }^{11}$ Alguns desses depoimentos foram explorados em outro lugar (NOGUEIRA, 2013). No entanto, aqui acrescentaram-se abordagens analíticas mais consonantes com discussões no âmbito da Antropologia das Emoções e aprofundou-se a análise sobre eles.
} 
segundo Coelho, Durão e Vianna (2012, p.214), de que a "etnopsicologia 'euro-americana' estaria estruturada em torno de duas oposições: emoção versus pensamento e emoção versus distanciamento".

O discurso do "princípio de imparcialidade" refere-se simultaneamente a ambas as oposições. A "imparcialidade" surge como uma justificativa racional (do pensamento) baseada no pressuposto de como deve ser o desempenho profissional (imparcial, distanciado) em uma organização estatal limitada por parâmetros administrativos e jurídicos ("respeito aos direitos humanos e do Estatuto do Estrangeiro").

Cabe lembrar que para Fineman (2001) existem três perspectivas sobre inter-relações entre emoções e razão no contexto organizacional: a de que as emoções perturbam a racionalidade, a de que podem ser úteis a ela e de que se trata de duas faces de uma mesma moeda. Quanto à primeira - que parece corresponder à visão do funcionário -, pressupõe-se que pessoas agem conforme suas percepções e, uma vez que estas "sofrem interferências de experiências afetivas e medo inconscientes, as ações daí decorrentes sempre serão enviesadas e passíveis de distorções" (GONDIM; SIQUEIRA, 2004, p. 217).

Outro grupo de funcionários (agentes e administrativos) da PF parece ir além do lema de "servir bem servido", ideal expresso no hino da categoria. Em particular no contato com os estudantes estrangeiros, eles acabam desempenhando papéis que ultrapassam as exigências obrigatórias dos cargos que ocupam, tomando atitudes que se baseiam na solidariedade e na empatia em relação ao "outro".

Dentro de uma interpretação mais psicológica, Marques (2004, p. 126) diz o seguinte sobre o que chama de "o calor e o frio na convivência organizacional", neste caso o "calor":

\footnotetext{
“argumentar sobre as razões que nos levam a correr o risco de ganhar nos levam a correr o risco de ganhar. Isso requer o uso da ideia de "parar-olhar-escutar" nos diálogos informais, fazendo com que as pessoas sejam atravessadas pelo desejo de ajudar "o outro" amorosamente (...)".
}

Compartilhando a ideia de que as emoções adquirem significados no plano da consciência e das interações sociais, e que "as emoções são tomadas como um idioma que define e negocia as relações sociais entre uma pessoa e as outras (LUTZ; WHITE, 1986 apud REZENDE, 2002, p.74), se colocar no lugar de ou ajudar o "outro" - "parar-olhar-escutar" - faz parte de um 
reconhecimento de si dentro do ambiente organizacional marcado pela racionalidade como alguém de "carne e osso", como dito por um membro da Delemig, e não como uma peça da engrenagem no modelo fordista ridicularizado no filme Tempos Modernos (1936), de Charles Chaplin.

Um dos agentes ouvidos da PF conta que os "atrasos da carteira sensibilizam mais os funcionários pelos estudantes, pois eles em geral têm poucos recursos". Perguntado se essa sensibilidade ou aproximação relativa quanto às questões dos estudantes estrangeiros não causa problemas dentro da PF, ele disse que o principal é "resguardar a imagem da corporação, por exemplo, não ter uma má conduta, como estar embriagado, fazer piadas jocosas em relação aos colegas da PF e superiores hierárquicos, ou ferir a lei, claro".

Entre os problemas atuais que sensibilizam tais funcionários, o não pagamento da renovação - "pois não solicitou na data correta a prorrogação e não pagou a taxa na data por falta de dinheiro mesmo" - é o principal, já que estar na clandestinidade, nas palavras de um funcionário, "pode leválo para a cadeia ou para a deportação". Com isso, segundo ele, "tem gente [da PF] que só falta pagar a taxa, pois orienta sobre as possibilidades de resolução do problema...ver o estudante que quer fazer tudo direito mas não faz por falta de dinheiro, isso causa comoção". Entre as orientações, uma muito comum é dada em relação ao estudante que termina a graduação e ingressa na pós-graduação sem sair do país e voltar com outro convênio o que seria obrigatório. Nesses casos, a sugestão dos funcionários é que eles procurem a Justiça e consigam um mandato de segurança para assegurar o direito à permanência.

Conforme abordado em outro lugar (NOGUEIRA, 2013), tem-se, assim, que os funcionários da Polícia Federal seguiriam aquilo que poderíamos classificar como um referencial de legalidade, formalidade ou solidariedade quanto à relação que se estabelece entre eles e os estudantes.

Por referencial de legalidade, pode-se entender que a conduta de tratamento dispensado aos estrangeiros baseia-se no cumprimento das resoluções, das normas e das leis existentes. No plano que entendo por formalidade, a conduta está mais relacionada a procedimentos burocráticos e tratamento distanciado, formal. E, por fim, por solidariedade entendo que o tratamento dispensado se baseia em uma sensibilidade para o "outro" norteada por um afeto, levando o funcionário a ultrapassar as funções exigidas pelo cargo que ocupa para ajudar o estudante a resolver sua dificuldade. 
Neste último caso, a justificativa para essa conduta está representativamente presente na fala de um dos entrevistados: "Fico muito feliz em poder ajudar, principalmente quando vejo as pessoas em situação difícil, não apenas financeira, mas tento compreender esses (des)caminhos, essas exigências e os entraves legais. Me faz um enorme bem como ser humano". A renovação das estadas são as ocorrências mais comuns que envolvem a PF e os estudantes estrangeiros.

Eventualmente, porém, ocorrem situações que sensibilizam ainda mais os grupos pesquisados ${ }^{12}$. É possível perceber que o contato com casos de discriminação contra estudantes estrangeiros tende a ser um dispositivo de humanização que afeta boa parte dos membros do setor de migração que, para além do desempenho profissional, passam a ser afetados no nível dos sentimentos.

O depoimento de um funcionário da Delemig parece representar bem o que move alguns membros da Polícia Federal a serem menos impessoais no contato com os estrangeiros regularizados ou irregulares devido a problemas que fogem a seus controles: "A questão é que às vezes nós [os servidores públicos] não sentimos as necessidades que as pessoas [estrangeiros] sentem; não nos colocamos no lugar do outro". Assim, identificar-se com o estrangeiro é o primeiro passo para a possibilidade de uma interação mais solidária entre os representantes do estado e os estrangeiros.

Os limites entre o esperado, o aceitável e os "excessos" (este, termo nativo) são construídos pelo grupo. No que se refere aos "excessos" considerados por todos os entrevistados, as pessoas ouvidas no início da pesquisa relatam casos do tipo "ouvi falar", em especial sobre uma situação isolada de relacionamento mais íntimo entre eles. No que se refere a situações de grosseria ou rispidez, particularmente em João Pessoa, parece não ocorrer, de acordo com relatos de estudantes e funcionários da PF até 2012. Como diz um funcionário da PF,

“o pessoal conta sobre uma equipe de policiais que existia e que tinha uma interação frutífera, que criava laços. As pessoas

\footnotetext{
${ }^{12}$ Como o caso de uma violência sofrida por uma estudante africana dentro do campus da Universidade Federal da Paraíba (UFPB), em 2010, que envolveu xingamentos racistas, agressão física e minimização da gravidade do caso pela então delegada da Policia Civil responsável, que acabou sendo substituída, conforme foi amplamente noticiado pela imprensa (ver NOGUEIRA, 2013).
} 
chegavam receosas por estarem em instituição policial mas em particular os estudantes encontravam maior acolhimento [grifo meu], eram atendidos de forma mais simpática, provocando retorno dos estudantes. Quando havia festas das comunidades, eles chamavam os policiais para a sindicância e para a participação. Um deles foi nomeado embaixador da comunidade de Cabo Verde no Brasil".

Deve-se ressaltar que a palavra "acolhimento" foi utilizada pelo entrevistado. Pode-se perceber em várias situações relatadas que há um repertório que remete às ideias de bem-receber, ser acolhido e ser hospitaleiro com quem vem de fora. Em depoimentos colhidos com alunos da Guiné-Bissau, por exemplo, parte deles disse que a principal dificuldade da vida no Brasil era a "saudade da família" e o mais fácil era que a "sociedade paraibana é hospitaleira [grifo meu]" (mais adiante isso será mais bem discutido).

É importante que se diga que a maior parte dos relatos foi coletada entre 2009 e 2012. O acompanhamento das atividades da Delegacia a partir de 2013 vem ocorrendo de modo menos sistemático, tendo como referencial conversas informais com meu principal interlocutor. Dessas nossas conversas mais recentes, em maio de 2014, ele me disse que casos de funcionários mais "sensíveis para o outro" ou como o do "embaixador do Cabo Verde" são, nas palavras dele, "ponto fora da curva".

A leitura dele é que desde a greve da Polícia Federal, no primeiro semestre de 2013, ocorreu um recrudescimento dos policiais em geral, tendo inclusive aumentado a tensão entre delegados e peritos, de um lado, que possuem maiores salários, e agentes, escrivães e papiloscopitas, por outro. Na ocasião, delegados, peritos e administrativos não paralisaram, diferentemente de agentes, escrivães e papiloscopistas, causando um conflito claro de posições distintas entre os dois grupos.

Sobre a greve de 2013, trechos de matéria publicadas no portal G1, da Globo, em agosto daquele ano:

“Cerca de 200 policiais federais do Distrito Federal iniciaram nesta segunda-feira (19) às 11 h uma greve prevista para durar 48 horas. A categoria pede reestruturação da carreira com definição em lei das atribuições de escrivães, papiloscopistas e agentes. Os grevistas também pedem fim do assédio moral na PF.

Segundo o sindicato que representa a categoria e a assessoria de imprensa da Polícia Federal, todos os serviços prestados pela PF 
continuam funcionando normalmente, incluindo a emissão de passaporte. O Sindicato dos Policiais Federais no Distrito Federal (Sindipol-DF) informou que há cerca de 1.500 servidores da PF no $\mathrm{DF}$, incluindo delegados, peritos e servidores de carreiras administrativos - categorias que não paralisaram [grifo meu].

(...)

- Polícia Federal rejeita acordo e decide manter greve nacional

O presidente do Sindipol-DF, Flavio Werneck, reivindica que escrivães, papiloscopistas e agentes tenham equiparação salarial com as carreiras de agências reguladoras. Segundo Werneck, hoje o salário líquido inicial dos trabalhadores da PF é de aproximadamente $\mathrm{R} \$ 5$ mil e chega a cerca de $\mathrm{R} \$ 9$ mil em fim de carreira.

"Queremos o fim do apartheid profissional que hoje só permite que exista chefia para delegados e peritos [grifo meu]. Há um assédio moral constante e abusos no Departamento da PF. Hoje, o policial federal que trabalha em área fronteira no combate ao narcotráfico ganha R\$ 5 mil líquido, enquanto um delegado na sede ganha até R\$ 27 mil”, disse Werneck."(NERI, 2013) ${ }^{13}$."

Quase um ano depois, em junho de 2014, uma nova ação é organizada pelo sindicato:

“Objetivando prestar contas de nossas atividades, esta Diretoria Executiva vem, pelo presente, informar aos seus filiados as medidas adotadas no trimestre: março, abril e maio de 2014:

A) Ações sindicais:

1) Realizamos várias assembleias e reuniões com os nossos filiados residentes em João Pessoa, Campina Grande e Patos/PB, visando mantê-los informados sobre o andamento das negociações da reestruturação da carreira e salarial dos servidores do DPF;

2) Realizamos diversas paralisações, manifestações, panfletagem, passeatas, carreatas, visando conscientizar o governo federal da necessidade de implantar a reestruturação da carreira e salarial dos servidores pertencentes aos cargos de Agentes, Escrivães, Papiloscopistas Policiais Federais e do pessoal pertencente ao

${ }^{13}$ Fonte: Matéria intitulada "Policiais federais da PF fazem greve de $48 \mathrm{~h}$ por reestruturação da carreira", por Felipe Néri. Disponível em: http://g1.globo.com/distrito-federal/ noticia/2013/08/ policiais-federais-do-df-fazem-greve-de-48h-por-reestruturacao-dacarreira.html. Acesso em 30 de agosto de 2013. 
Plano Especial de Cargos do DPF" (Sindicato dos Policiais Federais, $2014)^{14}$."

Para meu interlocutor, a junção da situação política da greve aliada à renovação da Superintendência na Paraíba justificam um relativo pessimismo quanto à sensiblidade dos funcionários da PF de modo geral, ainda que, em sua avaliação, a renovação do quadro possa estar trazendo "gente nova" com "pensamento mais aberto".

Por outro lado, se é possível supor, como faz o entrevistado, que essas tensões na carreira funcional possam vir a gerar uma "dessensibilização" dos funcionários da PF, há outros movimentos que podem apontar em direção oposta. É o caso, por exemplo, da busca por formação em nível de pós-graduação em Programas com vieses analíticos afinados com o ideário dos Direitos Humanos, como na trajetória de um funcionário que, inclusive, defendeu no início de 2014 a tese sobre migrações de travestis da Paraíba que se prostituem na Italia, no Doutorado em Sociologia da Universidade Federal da Paraíba (onde também cursou o mestrado em Direitos Humanos), de caráter etnográfico e expressando pontos de vistas nativos.

Seja como for, a despeito das tensões existentes entre os vários níveis hierárquicos, é relativamente compartilhado dentro da corporação um sentimento de distinção em uma comparação com as outras polícias (Militar e Civil). Segundo a ótica de um funcionário, a distinção se apoia no fato de que a Polícia Federal "não se aproxima de uma criminalidade cotidiana, como estupro e homicídio, exceto pelo narcotráfico. Além disso, os salários mais altos reafirmam a distinção".

Por esse viés de interpretação, a solidariedade e a hospitalidade expressas por alguns membros da Delemig junto aos alunos internacionais em situações de dificuldade ao incorporarem o sentimento de distinção, talvez se aproximem da noção de compaixão, tal como apresentada e discutida por Coelho (2010) em pesquisa junto às vítimas de violência em suas residências. A autora lembra Miller (1997) e Clark (1997), para dizer que semelhante ao desprezo, a compaixão - no discurso das vítimas, "a pena" dos assaltantes - também carrega "o esforço de recuperação (...) de

\footnotetext{
${ }^{14}$ Fonte: Web site do Sindicato dos Policiais Federais da Paraíba. Disponível em: http:/ / www. sinpefpb.org.br/news.php. Acesso em: 09 de junho de 2014.
} 
um lugar de superioridade hierárquica no plano subjetivo" (p.269), já que:

"Para Clark, a compaixão é um sentimento assimétrico que, ao mesmo tempo em que é facultado pela ocupação de lugares socialmente distintos, concorre por sua vez para assinalar e reforçar essa assimetria entre aquele que dá e aquele que recebe compaixão (COELHO, 2010, p.279-280)".

Ainda que aqui se entenda os atos de membros da Delemig que ultrapassam as expectativas da imparcialidade, do distanciamento e da formalidade burocrática organizacional como "dádivas de hospitalidade", como nos lembra Montandon (2011, p.41), "nada é menos simples do que a hospitalidade", uma vez que entendida como uma dádiva, implica na doação da essência do doador ou daquele que acolhe. Para Perrot (2011), a "dádiva da hospitalidade" coloca questões diretamente relacionadas às noções de identidade de doadores e receptores, portanto, para o autor, “como a dádiva é 'mais mental que material' (AUROUX, p.64). Como o objeto dado veicula algo do doador, a dádiva põe em questão a identidade - a daquele que, dando, dá algo de si e, talvez mais ainda, a daquele que, recebendo, acolhe algo do outro" (idem $)^{15}$.

Desse modo, assim como a compaixão, nela está presente uma ambiguidade. Conforme Grassi (2011, p.45), a :

"hospitalidade se apresenta como uma ponte frágil e perigosa estabelecida entre dois mundos: o exterior e o interior, o fora e o dentro". Como tal, é possível entender os funcionários da PF que vão além das exigências do cargo como aqueles que, ao acolherem de algum modo os estrangeiros, tornam-se hospitaleiros.

A ambiguidade potencial do termo como posta por Grassi se encerra justamente na vivência situacional de funcionários e estudantes. As atitudes concretas dos funcionários da PF para com os estudantes é que definirão o caráter hospitaleiro do contato entre eles: a impessoalidade burocráticoformal incorporada pelos representantes do Estado ou, para além dela, a solidariedade envolvida em situações humanitárias assimétricas de ajuda

\footnotetext{
${ }^{15}$ Para uma discussão sobre a dádiva da hospitalidade presente na cooperação internacional, ver Silva (2008) e Nogueira (2014).
} 
ao "outro", ao "semelhante", como disse um funcionário da PF.

Especificamente no que se refere ao trabalho da Delemig, poder-seia acrescentar a própria ambiguidade da situação migrante e do papel do representante do Estado nesse contexto migratório. Os estudantes internacionais podem estar legais e regulares, legais e irregulares, ilegais. Os atos não permitidos que cometem em solo estrangeiro e o não cumprimento de alguma norma burocrática-formal (ou mesmo legal) podem imediatamente transformar as relações estabelecidas de modo hospitaleiro e solidário em interações marcadas pelo peso do cumprimento do dever por integrantes da Polícia Federal - que é antes de tudo uma organização burocrática, de controle e investigação.

Quando isto ocorre, há uma ressignificação das emoções, sentimentos e afetos envolvidos na relação entre estrangeiros e representantes do Estado. Nessas situações, o que acolheu (o país representado por um funcionário público) passa a ser aquele que diz que o hóspede (o estrangeiro) não é mais bem-vindo. E aí, discursos, práticas e concepções de si se voltam para a racionalidade estatal em que, em princípio, as emoções devem estar ausentes.

\section{Palavras finais}

O aumento do número de imigrantes no país combinado a uma política externa voltada para a cooperação internacional "Sul-Sul" - portanto com princípios de simetria de poder e horizontalidade - exige novas demandas do governo brasileiro. Entre elas, políticas públicas mais atualizadas, agentes mais bem preparados para lidar com essa realidade migratória e acompanhamento mais cuidadoso por parte de pesquisadores desse cenário contemporâneo, incluindo-se como objeto de estudo o aparelho estatal com quem os estrangeiros travam os primeiros contatos e também para quem devem se reportar periodicamente.

Ainda que, como observado por Vieira (1999), os imigrantes devam ser tratados a partir da garantia de proteção da dignidade da pessoa pelo simples fato de "ser humana", as situações concretas que envolvem representantes das organizações do Estado e estrangeiros nem sempre apontam para um entendimento de que se trata de interações entre pessoas. De um lado, representantes públicos, com seus referenciais de valor, crenças, gostos, hábitos, sentimentos, trajetórias, expectativas de vida, etc. De outro, 
do estrangeiro, ocorre a mesma coisa. Como as interações ocorrem dentro de limites (físicos e simbólicos) organizacionais claros, muitas vezes sob a égide da imparcialidade, da racionalidade burocrática e do distanciamento construído entre o "Estado" e o "indivíduo", aquele que chega é visto como uma ameaça e o que recebe torna-se objeto de ansiedade e medo.

O caso aqui estudado das percepções dos funcionários da Delemig, em sua relação com estudantes estrangeiros (e, em última instância, das interpretações que fazem sobre seu ofício em atividades no contato com eles), torna-se privilegiado para se pensar se e o quanto as emoções, os sentimentos e os afetos fazem parte do cotidiano organizacional. Isso a despeito dos ideais de separação entre razão/pensamento/distanciamento versus emoção no ambiente de trabalho, e as condutas que nele se desenvolvem.

As interações e relações construídas nos contatos periódicos entre os membros da Delemig e os alunos internacionais abrangem tanto imaginários e políticas migratórias baseadas na crescente criminalização do migrante quanto interpretações sobre como desempenhar as obrigações funcionais a partir de ideais subjetivos de hospitalidade e solidariedade perante "o outro", sem que se fira alguma norma profissional ou jurídica.

Nesse sentido é que as relações puderam ser percebidas como "normais", por aqueles (PF e estrangeiros) que seguem o "princípio da imparcialidade" alegado por um agente, ou "boas" e "amistosas", como dito por um estudante africano, por aqueles que ultrapassam os limites formais que o respeito constitucional e internacional exigem do servidor público quanto aos direitos humanos.

Ser hospitaleiro (com toda a ambiguidade que seu significado carrega) e solidário, sem nunca esquecer os limites profissionais que a organização estatal lhes impõe, vem sendo o grande desafio dos membros de instituições policiais que exercem funções burocráticas, de controle e investigação.

No outro polo da interação, mesmo que não tenha sido o foco neste artigo, os estudantes internacionais regulares no país também estão emocionalmente referidos à ideia de que qualquer deslize pode significar a volta para o país de origem - o que gera medo e ansiedade na expectativa do contato com a Polícia Federal.

Termino, pois, com um breve relato que presenciei em sala de aula, envolvendo um estudante do Cabo Verde:

“No intervalo da minha aula, Otávio [nome fictício] sai da sala, como os demais alunos. Em dez minutos todos deveríamos 
retornar. Meia hora se passa, até que ele volte, pálido, com uma correspondência na mão. Pergunto se está tudo bem. Ele me diz: 'no intervalo, a secretária [do mestrado] me entregou uma correspondência da Polícia Federal. Desde aquele momento estou sem coragem de abri-la'. A turma, composta por estudantes com formação em várias áreas na graduação, se manifestou logo dizendo que, se houvesse algo errado, ali tinham dois advogados para ajuda-lo. Isto o encorajou a abrir a carta, com as mãos trêmulas. Após a leitura, deu um suspiro aliviado, dizendo: 'é só um comunicado avisando que preciso renovar minha licença'".

Situações como essa colocam o desafio para ambos - anfitriões/ representantes do Estado brasileiro e hóspedes/estudantes estrangeiros - sobre como fazer das interações que são simultaneamente formais e pessoais referências do bem-receber, por um lado, e do ser (e o sentimento de ser) um hóspede desejado, por outro.

\section{Referências}

BARCELLOS, Claudia Rezende.

(2002). Mágoas de amizade: um ensaio em Antropologia das Emoções. Mana, 8 (2), p.6989.

BOURDIEU, Pierre.

(2007). A Distinção: crítica social dojulgamento. São Paulo, Edusp.

CLARK, Candace.

(1997). Misery and company sympathy in everyday life. Chicago \& London, The University of Chicago Press.

COELHO, Maria Claudia.

(2010). Narrativas da violência: a dimensão micropolítica das emoções. Mana,16 (2), p.265-285.

COELHO, Maria Claudia; DURÃO, Susana; VIANNA, Adriana.

(2012). Antropologia com Emoção. Entrevista com Catherine Lutz. Mana,18 (1), p.213-224.

ETCHEVERRY, Daniel.

(2007). A documentação de estrangeiro no Brasil: seus caminhos e significados. In:
Denise Fagundes Jardim (Org.); Cartografia da imigração: interculturalidade e políticas públicas. Porto Alegre, Editora da UFRGS.

FINEMAN, Stephen.

(2001). Emotions and organizational control. In: Roy Payne; Cary L. Cooper (Eds.); Emotions at Work: theory, research and applications for management. Chichester, John Wiley \& Sons. p. 219-240.

GONDIM, Sonia Maria Guedes, SIQUEIRA, Mirlene Maria Mathias.

(2004). Emoções e afetos no trabalho. In: José Carlos Zanelli; Jairo Eduardo Borges-Andrade; Antônio Virgílio Bastos Bittencourt (Orgs.); Psicologia, Organizações e Trabalho no Brasil. Porto Alegre, Artmed. p.207-235.

GRASSI, Marie-Claire.

(2011). Hospitalidade. Transpor a Soleira. In: Alain Montandon (Dir.); 0 Livro da Hospitalidade. Acolhida do Estrangeiro na História e nas Culturas. São Paulo, Editora Senac São Paulo. 
MARQUES, Juracy Cunegatto.

(2004). Relações interpessoais e apoios afetivos: o calor e o frio na convivência organizacional (Capítulo 4). In: Cláudia Bittencourt (Org.); Gestão Contemporânea de Pessoas: novas práticas, conceitos tradicionais. Porto Alegre, Bookman. p.119131.

MENEZES, Lená Medeiros de.

(2007). Movimentos migratórios: resgate necessário nas Relações Internacionais. In: Mônica Leite Lessa; Williams da Silva Gonçalves (Orgs.); História das Relações Internacionais. Teorias e Processos. Rio de Janeiro, Eduerj.

MILLER, William Ian.

(1997). The anatomy of disgust. Cambridge, Harvard University Press.

MONTANDON, Alain (Dir.).

(2011). Introdução. In: Alain Montandon (Dir.); 0 Livro da Hospitalidade. Acolhida do Estrangeiro na História e nas Culturas. São Paulo, Editora Senac São Paulo.

NOGUEIRA, Silvia Garcia.

(2014). Cooperação educacional Brasil-TimorLeste e a dádiva da hospitalidade paraibana: reflexões sobre uma experiência. In: Miriam de Oliveira Santos; Regina Petrus; Anita Loureiro de Oliveira (Orgs.); Recortes interdisciplinares sobre migrações e deslocamentos. Rio de Janeiro, Leo Christiano Editora Ltda. p. 107120.

(2013). Entre o burocrático-legal e a hospitalidade: os estudantes internacionais na Paraíba e a Polícia Federal. Interseções, vol.15, n.1.
PERROT, Danielle.

(2011). Dádiva. Hospitalidade e reciprocidade. In: Alain Montandon (Dir.); 0 Livro da Hospitalidade. Acolhida do Estrangeiro na História e nas Culturas. São Paulo, Editora Senac. p.63-72.

PÓVOA-NETO, Helión.

(2005). A criminalização das migrações na nova ordem internacional. In: Helión Póvoa Neto; Ademir Pacelli Ferreira (Orgs.); Cruzando Fronteiras Disciplinares. Um panorama dos estudos migratórios. Rio de Janeiro, Revan (Núcleo Interdisciplinar de Estudos Migratórios - NIEM).

SILVA, Kelly Cristiane.

(2008). A cooperação internacional como dádiva. Algumas aproximações. Mana,14 (1), p.141-171.

VIEIRA, Oscar Vilhena.

(1999). Direitos Humanos 50 anos depois. Cadernos de Direito e Cidadania I, Dialogando sobre Direitos Humanos. São Paulo, Idec.

\section{Recebido em}

dezembro de 2016

\section{Aprovado em}

março de 2017 